\title{
The Crisis of Modern Virtues and the Possible Ways to Rebuild the Virtues
}

\author{
Kuangfei Xie \\ Humanity and Politics Department of Nanjing University of Traditional Chinese Medicine, Nan Jing, China
}

Email address:

09110010012@fudan.edu.cn

To cite this article:

Kuangfei Xie. The Crisis of Modern Virtues and the Possible Ways to Rebuild the Virtues. Education Journal. Vol. 4, No. 5, 2015 , pp. $245-250$. doi: $10.11648 /$ j.edu.20150405.19

\begin{abstract}
In spite of the fact that we have made much progress in the economic development and the accumulation of the material wealth, the morality on the whole is on the decline and the modern people are faced with the serious crisis of virtues, among which the soulless excellence brought about by the emptiness of moral education is one of the most serious ones. The virtues can and should still be taught in schools, but by the more effective methods that can be accepted by the modern students. To prevent the young people from consciously escaping from pursuing the virtuous life and overcome the paradox of the moral education, we need to take the emotional dimension of virtue education into account. Virtues are supposed to be deeply rooted into the real life and the virtue education can not be isolated from the reality life.
\end{abstract}

Keywords: Virtues, Crisis of Virtues, Practical Wisdom

\section{Introduction}

With the complicated modern society on the whole getting better and better, are the modern people themselves becoming morally and virtuously better? Tremendous rewards have been lavished on the tangible and measurable material things, while the really noble virtues have been marginalized or even entirely ignored. Historically speaking, the material and economic achievements of mankind do not necessarily bring about the corresponding progress or improvement of general morality among man. Quite on the contrary, in many cases, the morality, in general, has been on the decline. Virtues and happiness, which, in ancient times, were not originally separate from each other, have currently become so isolated from each other that virtues seem to have nothing to do with happiness at all. It is because of the existence of virtues, or the sense of dignity that" It is better to be a human being dissatisfied than a pig satisfied and it is better to be Socrates dissatisfied than a fool satisfied".[1] When the modern people are confronted with the crisis of virtues, they are also inevitably confronted with the crisis of happiness as well the crisis of identity. The essence that makes us who we are as a whole and genuine person is like a very tender and fragile plant, easily killed or ruined, not only by the lack of the proper cultivation or education, but also by the general degradation and deterioration of the social morality. Similarly, the initial capacity to enjoy and create the true and high happiness that is deeply rooted into the virtues can also die away if the social community in which they live can not effectively provide them with the favorable conditions that are beneficial for the healthy growth of the virtuous mentality. Next to the objective alienation of the industrial society, the principal cause which leads to the crisis of virtues is the want or lack of the appropriate moral education. A morally and virtuously cultivated mind is capable of finding the inner and inexhaustible beauty of the virtues. By analyzing the fundamental reasons behind the crisis of virtues, we are actually taking the critical approach to the existing moral education.

\section{The Soulless Excellence: The Emptiness of Moral Education}

With either the dogmatic moral rationalism or the vulgar skeptical moral empiricism being dominant in the current moral education practice, the moral education, in general, has been degraded into the pursuit of the soulless excellence. Consequently, the emptiness of moral education has resulted in the hollowness of the virtuous agents. One the one hand, the radical transformation of the modern society has resulted in the disintegration of the traditional moral education and the traditional virtues structure; on the other hand, the transition 
towards the modern values or virtues framework has not yet been finished. In addition, following the rapid development of globalization, the cultural diversity has become an inevitable trend, which has directly led to the moral relativism or even the moral nihilism. While the scientific knowledge concerning how to be vulgarly and secularly successful has led the way and is far in advance, the wisdom concerning the noble art of virtuous life is still struggling with the rudiments. In spite of the fact that it is commonly acknowledged that knowledge is power, the most significant knowledge about the good and how to live the virtuously good life has been largely ignored. When the modern society, in its time of upheavals in values and opinions, can no longer provide us with the solid life soil in which we can be who we truly are and what we ought to be, we are inclined to turn to the moral education for the ultimate guidance, which again is a big disappointment. Without the effective cultivation of the eternal virtues, it would be impossible for the moral agents to attain the inner harmony or the inner integration in such a disintegrated and commercial modern society. The most fundamental and serious problem facing the education of the modern society is, undoubtedly, emptiness. What shall we gain, if we have conquered the whole world and even the outer space with the help of the modern science education, but have lost our souls? The education without the emphasis of virtues cultivation is the hollow education, however advanced it is in terms of the development of the science and technology. And the hollow education can only produce the hollow people. What the modern moral education suffers most from the crisis of modernity is the essence and the soul of its work, which degenerates into either the hollow propaganda or the meaningless preaching.

\subsection{Should and Can the Virtues Still Be Taught}

While the modern education has, at least technically, set the young people free, it has also contributed quite a lot to their feeling increasingly alienated and dehumanized. Virtues seem to be the distant illusion, which looks charming but so unrealistic. Education is also a mirror of the society and the illness of the modern society has surely exerted tremendous influence upon its development. Too much importance has been attached to the cultivation of the individuality and the uniqueness of personality, with the universal virtues, such as compassion, tolerance, love, and temperance having long been ignored and forgotten. "Freedom, though it has brought him independence and rationality, has made him isolated and, thereby, anxious and powerless." [2] In a word, the modern people are simply too free and individual to be virtuous and compassionate. Freedom can not be separated from responsibility, which is one of the most crucial virtues of mankind. Virtues are alternately concerned with the moral theory about virtues and with the practical behavior. Virtues should be taught and can be taught, but must be taught wisely and flexibly. The essential aim of education, is to educate the person to be the real person in the real and complete sense, not just to make the person become a certain kind of professional person. Without the necessary virtues serving as the solid basis, all the accumulated knowledge and skills would be detrimental and harmful to the happiness of the individuals and the society as a whole. The essence of the virtuously good life is the fundamental principle that the virtuously good life is good of itself, being not dependent on the external circumstances or the exterior factors, such as wealth and social status. What makes us persons is not only our rationality, but also our virtues with the emotional dimension. Therefore, to be a complete person is to be genuinely virtuous. It takes the effective virtue education to raise the people from the state of nature to the state of virtues. Even though the human nature is born to be originally good, it would also be corrupted and degraded if it is not preserved by the sound virtue education. Virtues make the lasting happiness based on autonomy rather than on heteronomy possible. Only the happiness based on virtues is worth having and pursuing. As the supreme good, virtue, without a doubt, constitutes the ultimate purposes of any form of modern education. Besides, virtue and happiness are closely interwoven with each other and can not be separated. We can not elaborate on the happiness without talking about virtue.

\subsection{Rootless Virtue: Can Virtue Be Isolated from Life}

When virtue becomes too noble or too high to be approached and learned, it will inevitably degenerate into the abstract game of virtue scholasticism and dogmatism. Just like virtue is basis of happiness, life also constitutes the root of virtue. To inspire the living power of virtue, it is necessary to make virtue be deeply rooted into life itself. Virtue does not merely belong to the realm of ivory tower. Virtue comes from the reality of life and is supposed to return to life. Although virtue can be taught, it does not mean that there is short-cut to virtue, as if just by reading the books of virtues and listening to the lectures with regards to virtues we can become virtuous and moral overnight. To truly cultivate virtue, the root of happiness, no one can be saved the difficulties, or pleasure, of personally touching, feeling, and experiencing the virtues themselves. Virtue ethics theory is never the substitute for virtues themselves. In order to revive and revitalize virtue ethics in modern times, one of the most significant and urgent things is to humanize the virtues by making virtues go back to the real life world. In some sense, the current moral education has been dominated and even kidnapped by the epistemology. The real essence and vigor of virtue has largely been covered up and even ruined by the endless and insignificant abstract analysis of the concepts and terminology concerning virtues, totally ignoring and neglecting the soil of life itself. The real purpose of virtue ethics is not to equip us with the impractical knowledge regarding how to live a good life, but to provide us with the whole picture of life wisdom that can truly guide us towards the essential issue of how to be a morally good person in a naturally sustainable way. To truly understand and practice any specific virtue, we ought to know the life, reality and historical background on which the virtue is grounded, as well as under what circumstances the virtue is constructed is formed. While the core value of the virtue remains fundamentally the same, the extended and corresponding 
meanings of the virtue tends to be more or less changed or modified.

Virtue without life, just like trees without roots, can not grow up or help the virtuous agents grow up. In addition, educations without virtues, or virtue without life, can neither save us from despair and unhappiness, nor supply us with the undying courage and faith to pursue the happiness and good life. Ethics is the study of the ideal conduct or what a real person ought to be and ought to do. Just as Socrates put it," The highest knowledge is the knowledge of good and evil, the knowledge of the wisdom of life."[3] In terms the modern education on the whole, including moral education, the root of the crisis lies in the basic fact that we are putting the cart before the horse, putting too much stress upon the trivial and insignificant aspects of education but totally ignoring and marginalizing the truly essential soul of education: cultivating the morally whole person.

\subsection{Escaping the Virtue: The Paradox of Moral Education}

Originally, virtue is appealing and charming. Pursuing the virtuous life means pursuing the happy and harmonious life. The originally good and benevolent human nature is the root of virtues. In some sense, virtue, by itself, is what Pythagoras called the highest music. [4]

However, the modern world is out of joint and it can even be said that it is essentially a morally tragic era in which the traditionally good virtues have been broken and disillusioned into the disintegrated pieces. In the modern society, it is no longer the virtuous inner wealth that matters supremely, but the outer wealth and tangible social status that matters most. The predominant view with regard to virtues seems to be like the doctrines of Nietzsche, which claims that "Nature is beyond good and evil; that by nature all men are unequal; that morality is an invention of the weak to limit and deter the strong; that power is the supreme virtue and the supreme desire of man". [5] Compared with the previous ages, the modern life of the modern people is more based on expediency than on the lasting principles of virtues. Virtues are not supposed to be far away from man, nor should they be too high and noble for the ordinary people to reach them. Virtues exist to make us become better people, not the perfect and flawless people, and they exist to make us know ourselves, not deny ourselves.

\section{The Closed Hearts: The Emotional Indifference Behind the Virtue Crisis}

Eventually, it is not the logical minds, but the emotional hearts that constitute foundation of the virtues and the virtuous life. Virtue ethics is mainly concerned about the inner universe, not the natural outer universe. To really understand the fundamental causes resulting in the virtue crisis, we need to ask the following questions: What exactly is man? What is the essential meaning of virtue? What kind of role does the emotion play in the formation process of virtue? A disintegrating traditional collectivism has largely weakened the fundamental basis of virtues, worse still, it has cut off the strong link between the virtues and emotions. Through the gradual stages of industrialization and globalization, as well as the gradual stages of corresponding morality degeneration or decline, the existence of each individual has become the existence of atom or monad, being increasingly closed and isolated from each other. Owing to the closed minds and isolated hearts, virtues, in the eyes of many people, are neither universally beautiful nor individually agreeable. The emotional charm of virtues is the profound source of the attraction of virtues to the virtuous agents. Only when the virtuous agents are emotionally attracted to be after virtues can the virtues be deeply rooted into the hearts of the virtuous agents. Any virtues that are imposed upon the moral agents can not be expected to last for long. The judgment of the beauty of virtues does not rest on the abstract and cold moral concepts or rules, but on the spontaneous virtuous emotions. The traditional virtue system which keeps an appropriate balance between the mind and the heart or the reason and emotion is not only the source of modern virtue, but even now its life-supplying roots. Unfortunately, the virtue ethics has now been brought from the main street to the academic street, or from the market place to the ivory tower, as a consequence, the rational objectivity, or the emotional indifference, has dominated the field of moral education.

\subsection{Practical Life: The Morally Forgotten Horizon}

The highest virtue is inseparable from the most practical life. Virtues are supposed to be lived and serve as the practical guidance to better life. As Plato puts it," All virtues except wisdom are generated in the soul by habit and exercise"[6] As a matter of fact, even the virtue of wisdom, essentially comes from the practical life. Virtues, whether they be integrity, courage, temperance, or wisdom, largely originate from education, custom, tradition and the society as a whole. The practical life promotes the cultivation of virtues from two directions. On the one hand, when the society is well-ordered, it can naturally direct the people from the state of nature to the state of virtue. On the other hand, when the society is not well-ordered, with the Roman Empire being a good case in point, it can also provide the people with the opportunities to reflect and reexamine their identity, cultivating the virtue of being peaceful in chaos.

The really practical life, namely the real life based the genuine life experience, is dramatically different from the modern or post-modern life that has been profoundly shaped and alienated by the powerful science and technology. If not properly handled, science and technology would not save us, but ruin us. Thanks to the rapid development of science and technology, our life is seemingly happier, but not more virtuous. In contrast to the amazing advancement of science and technology, the morality of mankind has been corrupted to a great extent.

It is in the practical life or the community life that man's original moral feeling of sympathy or compassion is improved and even sharpened. Likewise, it is also in the practical life that the virtues of consideration and kindness are cultivated. 


\subsection{Emotions, Happiness, and Virtues: Inseparable and Interconnected}

Happiness on the basis of virtues is not only the happiness for oneself, but also the happiness of all concerned. What Adam Smith calls pity or compassion constitutes the initial seeds of virtues and characters." This sentiment, like all the other original passions of human nature, is by no means confined to the virtuous and humane, though they perhaps may feel it with the most exquisite sensibility. The greatest ruffian, the most hardened violator of the laws of society, is not altogether without it."[7]

Emotions are not equivalent to the natural feelings, rather, emotions are the morally elevated feelings. When people simply follow the natural feelings, they will pursue the desires without limit, but when the moral agents follow the moral emotions, the will pursue the disciplined and rationally limited pleasures. Since the human desire is unsatisfied, the unlimited pursuit of the satisfaction of the sensual desires will be in vain. The fundamental function of virtues is the transformation of destiny, not just the instilling of information concerning happiness.

It is just owing to the virtues that people come to realize the fact that the desires are essentially unquenchable and only by living the virtuously contented life can we be moderately and sustainably happy. The human desire tends to lure us to" Gather ye rosebuds while ye may", but the moral emotions prompt us to ask and answer the following questions: For whom we gather rosebuds and for what we gather rosebuds?

To profoundly understand the relationship between virtue and happiness, we need to understand what exactly virtue consists in or what the fundamental structure of virtue is. Virtue means the proper combination of both the moral emotions and moral practical wisdom that aims at the ultimate happiness of the moral agents. When the emotional dimension of virtue is forgotten, virtue stops being virtue in the real sense.

\subsection{Isolation Breeds the Emptiness of Virtue}

As Adam Smith puts it, "As we have no immediate experience of what other men feel, we can form no idea of the manner in which they are affected, but by conceiving what we ourselves should feel in the like situation." [8] Being not only socially and economically, but also emotionally and morally connected constitutes the real foundation of the virtues. However, with the principles of market economy going into the fields of education and morality, the society has been unconsciously turned into the market society, resulting in the deterioration of virtues and the decline of morality. The moral emotions are replaced by the utilitarian calculation of self-interest. As a consequence, it looks to be more profitable and worthwhile to do what is not virtuous rather than virtuous. Virtues, are not admired, but ridiculed.

In fact, the fellow feelings for the sufferings or the happiness of other people are the essential factor that distinguishes us as the people from the animals. As a morally genuine person, he can put himself into the shoes of others and even the destiny of others. Emotions like pity and compassion, have consistently helped mankind to restore the eternal dignity. The morally isolated state of life has greatly strengthened the egoistic side or the evil side of human nature, while the noble emotions like sympathy have enhanced the altruistic and benevolent side of human nature.

Just like virtues, the various emotions are also mutual and contagious. According to Adam Smith," and this correspondence of the sentiments of others with our own appears to be a cause of pleasure, and the want of it a cause of pain. Sympathy, however, enlivens joy and alleviates grief". [9]In this sense, the socialization process also involves the process of emotionalization. It is by virtue of the gradual enhancement of the corresponding mutual emotions between the virtuous agents that the corresponding virtues are formed. By doing the virtuous things or feeling the effects of others' virtuous behavior, we create the moral emotions in accordance with the virtuous acts, which in turn shape or purify our virtues.

\section{Beauty and Art: The Real Essence of Virtue}

The following question waits for the virtue ethics scholars to answer: Why were virtue ethics scholars, whose ideas and proposals were often so profound and thought-provoking, increasingly regarded by general public as impractical and arrogant, mechanical? The important reason is that virtue ethics, as a charming academic discipline, has intrinsically lost its artistic dimension.

The lack of the artistic dimension of virtues has disoriented the virtue ethics, wiping out temporarily the essential beauty and functions of virtues, and blurring the whole and clear picture of virtue ethics. In the modern age of anxiety and emptiness, so much confusion and bewilderment has paralyzed the virtuous capacity of the moral agents. Living the truly peaceful and virtuous life is the only possible way for the modern people to overcome the sense of helplessness and despair. But why do they consciously or unconsciously choose to escape the virtues? One of the fundamental reasons is that virtue ethics has been so abstracted and cold that it is no longer artistically appealing and attractive to the general public.

The primitive and originally beautiful virtues have been so repressed and marginalized that the moral agents have almost completely lost sight of the artistic dimension of virtues. The loss of the artistic dimension of virtues, during the transitional period of modern values, has been manifested in all aspects of virtue ethics, whether it be the teaching process of virtues or the learning process of characters.

\subsection{The Inner Beauty or Harmony Being Ruined: Identity Crisis}

The ultimate beauty of virtues lies in the inner beauty or the inner harmony of virtues. With the inner harmony within, 
comes the outer harmony of the outer life. However, the modern dramatic upheaval of values has led to the severe crisis of identity. The modern people are extremely confused and puzzled about who they are. There is a sharp contrast between what are morally taught to the modern people and what they really feel and experience in the practical life. The confusion of the modern people in the current conflict of values has tremendous negative impacts upon the artistic dimension of values. In the eyes of the modern people, at least for some time, the values taught in the ivory towers are no longer virtuously harmonious and beautiful, but are full of deceptions and lies. Arthur Miller's classic masterpiece Death of Salesman has vividly demonstrated this point.[10]

Is might really right? Or is the traditional virtue really what Nietzsche called the slave-morality? Shall we seek the virtuous life, or shall we seek the prestige and wealth? Should we choose the less traveled virtuous road or just follow the majority? Faced with the morally puzzling questions or moral dilemma, we need to be fully aware of who we truly are and what kind of person we ought to be before we can make the morally wise decisions. But the identity crisis caused largely by the lack of the inner stable virtues has made it rather difficult for us to make the right moral decisions.

\subsection{The Core of Virtues: Simplicity and Integrity}

The complicated nature of the moral affairs of mankind has made it almost impossible for us to make the perfect creed of behavior, and virtue ethics is no exception at all. Virtues derive the intrinsically but universally binding force from the simplicity and integrity, which constitutes the core inner beauty of virtue ethics.

"When Spinoza in the seventeen century used the word reason, he meant an attitude toward life in which the mind united the emotions with the ethical goals and other aspects of the whole man".[11] Originally, virtue is also a concept with integrity, describing what a whole person needs to live a wholly happy life. The consistent emphasis on the virtue agents, or the people, rather than the moral rules or moral principles, essentially constitutes the most significant distinctive characteristic of virtue ethics.

Only virtuous people can truly enjoy what they have and what they experience. The virtuous humanism, mainly consisting of such universal moral precepts as "Do onto others what you would have others do onto you" or "Do not do onto others what you would not have others do onto you" , is symbolic of the integrity and simplicity of virtues. Without the simplicity and integrity serving as the core of virtue, virtue will be felt as an obligatory burden rather than the beautiful roots of life.

The integrity of virtue also means that being virtuous does not only mean being prudent, enduring the present pains for the sake of the long-term happiness, but also means being passionate and enthusiastic, seizing the present and making the best use of the present. The person who is attracted by virtues and is determined to live the virtuous life will not go to any extreme. Instead, he will accept the doctrine of the mean, taking the middle course and being always moderate.

\subsection{Reviving Virtue: Turning the Crisis into Opportunity}

The virtuous meaning of crisis is that, essentially speaking, in crisis, we can create the opportunity to improve or even make a breakthrough. In spite of the above-mentioned crisis, virtues and virtue ethics shall overcome in the end and will, consistently and inevitably, provide mankind with hope of a better future.

Virtues are more than a list of names of various, specific and isolated virtue. The essence or soul of virtue is also beyond the mere talk and elaboration of the systematic and logical analysis of virtuous concepts. To save virtues, or to prevent virtues from being ruined by the crisis, whether it be the crisis of modernity or the crisis of moral education, we need to reiterate and restore our faith in living virtuously. The abstract rules or theories with regard to virtues are never the whole and real picture of virtue. The heart and soul of virtue lies in the life, the virtuous life on the basis of the imperfect but real world. Virtuously, people can, by his free will, choose to yield to the reality without yielding his inner virtuous harmony and dignity. In spite of the superficial connection between the modern people brought about by the technological development, they have lived curiously isolated from each other, shut in with one another in each individual mental prison. The sense of mental isolation inevitably intensifies the sense of helplessness and hopelessness. Therefore, overcoming the sense of isolation and strengthening the sense of being emotionally and virtuously united can eventually help the modern people regain the virtuous and happy life.

Due to the extremely complex nature of human virtues, virtue ethics is certainly a comprehensive discipline and it is concerned with all the psychological, ontological, and epistemological questions concerning virtues, but, above all, it is concerned with the most important question: How shall I live and what shall I live for? All roads lead to Rome and all aspects of the research work concerning virtues lead to this central task. The fundamental problems of virtue ethics and happiness definitely can not be merely limited to the narrow academic field with the dogmatic writing style and too many abstract terminologies, but rather, it has, intrinsically and internally, the appealing power to the general public and, therefore, should be made, both theoretically and practically, accessible to the general public.

With the meaningful chain connecting the traditional values and modern virtues being radically broken, the modern virtues have become rootless and lifeless, which also constitutes an important cause of the modern crisis of virtues. Thus, in order to get out of the crisis and rebuilt the fundamental roots of modern virtues, we need to throw all the thoughts of man back upon his inner or internal universe, namely, the inner virtuous world.

The most effective and convincing ethics concerning virtue is the ethics that can combine the virtuous rigor and the compelling guidance. 


\section{Appendix}

This study was supported by Nanjing University of Traditional Chinese Medicine. (Grant No. 13XSK11).

\section{References}

[1] John Stuart Mill: Utilitarianism, Liberty, Representative Government, Edited by H. B. Acton, Published by Everyman's Library, 1972, p.10.

[2] Erich H. Fromm: Escape From Freedom, Published by Henry Holt and Company, LLC, 1969, P. x.

[3] Will Durant: The Story of Philosophy, Published by Simon and Schuster, New York, 1949, p.3.

[4] Will Durant: The Story of Philosophy, Published by Simon and Schuster, New York, 1949, p.4.
[5] Will Durant: The Story of Philosophy, Published by Simon and Schuster, New York, 1949, p.7.

[6] Henry Sidgwick: Outlines of the History of Ethics, Published by Hackett Publishing Company, 1902, p.43.

[7] Adam Smith: The Theory of Moral Sentiments, Published by Liberty Fund, Inc., 1979, p.9.

[8] Adam Smith: The Theory of Moral Sentiments, Published by Liberty Fund, Inc., 1979, p.8.

[9] Adam Smith: The Theory of Moral Sentiments, Published by Liberty Fund, Inc., 1979, p.14.

[10] Rollo May: Man's Search for Himself, Published by W.W. Norton\& Company, Inc, p.48.

[11] Rollo May: Man's Search For Himself, Published by W.W. Norton\& Company, Inc, p,50. 